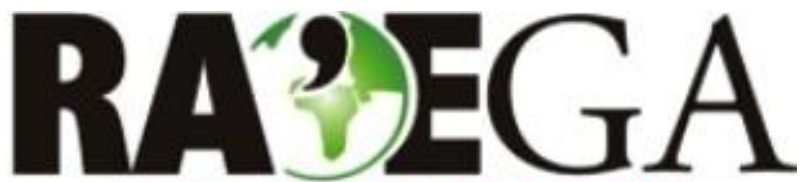

O ESPAÇO GEOGRÁFICO EM ANÁLISE

\title{
EXERCÍCIO PROFISSIONAL DO GEÓGRAFO NO ESTADO DO PARANÁ: CONVERGÊNCIAS E DIVERGÊNCIAS ENTRE A LEI DO GEÓGRAFO, AS DIRETRIZES CURRICULARES NACIONAIS, AS MATRIZES CURRICULARES E A PRÁTICA PROFISSIONAL
}

\section{PROFESSIONAL EXERCISE OF THE GEOGRAPHER IN PARANÁ STATE: CONVERGENCE AND DIFFERENCES BETWEEN GEOGRAPHER'S LAW, THE NATIONAL CURRICULUM GUIDELINES, THE UNDERGRADUATE PROGRAM AND PROFESSIONAL PRACTICE}

\section{RESUMO}

Tony Vinicius Moreira Sampaio ${ }^{1}$, Marcos Aurélio Pelegrina ${ }^{2}$, Carlos Henrique Sopchaki $^{3}$

Os Geógrafos possuem habilidades para realizar diferentes atividades. A aquisição das competências para o exercício destas atividades é função, principalmente, da Matriz Curricular cursada. Dado a diversidade de temas e o processo de modernização da Ciência Geográfica, por vezes as atividades desenvolvidas não condizem com as atribuições legais e competências profissionais fornecidas pelos cursos de graduação. Utilizando Anotações de Responsabilidade Técnica (ART's) recolhidas pelos geógrafos no estado do Paraná, matrizes curriculares dos cursos de bacharelado e, os instrumentos legais que regulamentam a formação e o exercício profissional (Lei 6.664/79 e Diretrizes Curriculares Nacionais - DCN's), este trabalho analisa e caracteriza a formação e as práticas dos geógrafos no Estado. Ainda, quantifica e espacializa a distribuição e atuação dos mesmos. A pesquisa mostra que as atividades registradas divergem da ênfase apresentada pela Lei, DCN's e matrizes curriculares dos cursos de bacharelado em Geografia no Paraná. Enquanto o Planejamento Territorial é a área de maior número de atribuições legais e, Análise Ambiental a de maior número de competências, Mapeamento/Geotecnologias corresponde à área de maior prática profissional, respondendo por $86,7 \%$ das atividades registradas por ART's no Estado. As ART's mostram que a atuação dos geógrafos se faz em praticamente todo o Estado, contudo com diferentes intensidades.

PALAVRAS-CHAVE: Bacharelado em Geografia; Formação Acadêmica; Anotação de Responsabilidade Técnica (ART).

\section{ABSTRACT}

The Geographers have ability to perform different activities. The acquisition of this competence for the exercise of these activities is due mainly to the undergraduate program. Given the diversity of issues and the process of modernization of Geographical Science, sometimes the activities are not consistent with the capacitance and professional skills provided by undergraduate courses. Using the Technical Responsibility Subscriptions (TRS's) collected by geographers in the state of Paraná, programs of bachelor's undergraduate courses and legal instruments of the training and professional practice (Law 6.664/79 and National Curriculum Guideline - NCG), this paper analyzes and characterizes the training and practices of geographer in the state. Still, quantifies and spatializes the distribution and performance of the same. This research shows that the activities recorded by TRS, diverge from the emphasis given by Law, NCG and curricular program of geography bachelor's courses in the Paraná. While the Territorial Planning is the area of highest number of capacitance and, Environmental Analysis of the greater number of skills, Mapping/Geotechnology matches the area of greatest professional practice, accounting for $86.7 \%$ of the activities recorded by TRS in the state. The TRS show that the work of geographers is done in virtually the entire state, but with different intensities

KEY-WORDS: BA in Geography; Academic education; Technical Responsibility Subscriptions

Recebido em: 29/07/2016

Aceito em: 22/08/2017

\footnotetext{
${ }^{1}$ Universidade Federal do Paraná, UFPR, Curitiba/PR, e-mail: tony2sampaio@gmail.com

${ }^{2}$ Universidade Estadual do Centro-Oeste, UNICENTRO, Guarapuava/PR, e-mail: marcospelegrina@gmail.com

${ }^{3}$ Universidade Federal do Paraná, UFPR, Curitiba/PR, e-mail: csopchaki@gmail.com
} 


\section{EXERCÍCIO PROFISSIONAL DO GEÓGRAFO NO ESTADO DO PARANÁ: CONVERGÊNCIAS E DIVERGÊNCIAS ENTRE A LEI DO GEÓGRAFO, AS DIRETRIZES CURRICULARES NACIONAIS, AS MATRIZES CURRICULARES E A PRÁTICA PROFISSIONAL}

\section{INTRODUÇÃO}

Geógrafo é a designação profissional dos habilitados em cursos de graduação em Geografia e, que atendem aos requisitos legais para exercício da profissão (BRASIL, 1979; BRASIL, 1980). Para os recém-egressos o exercício da profissão de Geógrafo só é permitido para portadores do diploma de bacharelado e, para os portadores de títulos de Mestre e Doutor em Geografia (BRASIL, 1985).

No âmbito de sua atuação os geógrafos exercem diferentes funções, as quais objetivam contribuir com a melhoria das condições de vida da população e do ambiente. Suas áreas de atuação refletem as atribuições profissionais definidas pela Lei Federal 6.664/79 (BRASIL, 1979) e, as habilidades e competências definidas pelas Diretrizes Curriculares Nacionais na Resolução 492/2001 (BRASIL, 2001), competindo ao CREA (Conselho Regional de Engenharia e Agronomia) a fiscalização do seu exercício profissional.

Diferentes concepções teóricas fundamentam a área de atuação e o objeto de estudo da ciência geográfica (CORREA, 2011; GODOY, 2011). Estas concepções influenciam as diferentes práticas profissionais resultando no desenvolvimento de atividades como: pesquisa, ensino (educação básica, técnica e profissionalizante), planejamento territorial, análise espacial, análise ambiental, turismo, produção cartográfica e tantas outras.

Os cursos de graduação em geografia no Brasil apresentam diferentes concepções, ora possibilitando a formação exclusiva de docentes, ora de bacharéis e ora conjunta. De acordo com o Ministério da Educação (MEC, 2016), existiam em 2015 no Brasil 495 cursos de Graduação em Geografia, considerando os cursos noturnos e diurnos, presenciais e a distância, de bacharelado e de licenciatura e os cursos públicos e privados.

Para que o geógrafo possa exercer seu papel, os cursos de graduação em Geografia devem contemplar três aspectos básicos:

1. Flexibilidade para se adequar e acompanhar a dinâmica dos problemas sociais e ambientais, os quais demandam constantes atualizações no que se refere ao arcabouço teórico, metodológico e instrumental da Ciência Geográfica;

2. A necessidade de retroalimentação da Ciência Geográfica, uma vez que os cursos de graduação são, ao mesmo tempo, locais de formação profissional e de desenvolvimento metodológico/científico e;

3. Condições para fornecer aos egressos as diferentes habilidades e competências necessárias à atuação profissional (BRASIL, 2003).

O Paraná se destaca no cenário nacional uma vez que é o segundo estado com mais cursos de graduação em Geografia no Brasil. Segundo eMEC (MEC, 2016) existem 28 cursos de graduação em atividade no Estado. Destes, dezenove são ofertados por instituições públicas de ensino, sendo 11 de licenciatura e oito de bacharelado. Este número somado à diversidade de atribuições e competências se reflete sobre os tipos e números de trabalhos registrados através das ART's (Anotações de Responsabilidade Técnica), anotação obrigatória para todo profissional em Geografia registrado no CREA.

Em função da diversidade de áreas de conhecimento abarcadas pela Ciência Geográfica e, das possibilidades de atuação profissional definidas pela Lei $6.664 / 79$, o exercício profissional do geógrafo é marcado por múltiplas facetas, as quais possibilitam ao mesmo atuar concomitantemente, ou não, em diferentes atividades. Estas atividades são parcialmente caracterizadas pelas ART's, as quais possibilitam conhecer o perfil dos mesmos em cada unidade da Federação.

Através destas anotações torna-se possível, também, espacializar o exercício profissional e, verificar a ênfase da atuação profissional, comparando-a com as atribuições regulamentadas pela Lei, bem como com as habilidades e competências ofertadas pelos cursos de graduação.

Neste sentido, o objetivo deste trabalho é comparar habilidades e competências profissionais relativas ao Geógrafo, descritas 


\section{EXERCÍCIO PROFISSIONAL DO GEÓGRAFO NO ESTADO DO PARANÁ: CONVERGÊNCIAS E DIVERGÊNCIAS ENTRE A LEI DO GEÓGRAFO, AS DIRETRIZES CURRICULARES NACIONAIS, AS MATRIZES CURRICULARES E A PRÁTICA PROFISSIONAL}

pelos diferentes instrumentos legais que regulamentam a formação e o exercício da profissão, com a prática profissional efetivamente desenvolvida no estado do Paraná, analisada a partir das anotações de responsabilidade técnica - $A R T^{\prime}$ 's registradas no CREA-PR até o ano de 2015.

Parte da pesquisa apresenta ênfase nos registros dos últimos cinco anos (período de 2011 a 2015), uma vez que para este período os dados fornecidos pelo CREA-PR possibilitam especializar as informações obtidas.

\section{MATERIAIS E MÉTODOS}

A pesquisa foi desenvolvida em quatro etapas: análise dos instrumentos legais (atribuições e competências), quantificação e caracterização da distribuição espacial dos geógrafos e ART's, tipologia das ART's e, análise das matrizes curriculares dos cursos de bacharelado do Paraná.

A análise dos instrumentos legais se baseia na análise e sistematização das atribuições e competências descritas na Lei do Geógrafo e nas Diretrizes Curriculares Nacionais (MARCONI; LAKATOS, 2003).

A quantificação e caracterização da distribuição espacial dos geógrafos e ART's e da tipologia das ART's foram realizadas com base na análise das Anotações de Responsabilidade Técnica (ART's) recolhidas por Geógrafos no estado do Paraná, no período de 2011 a 2015. Estes dados foram sistematizados e analisados quanto à frequência, recorrência, totais e médias, conforme propostas para tratamentos estatísticos de dados secundários (FALCO, 2008; MACEDO; MATOS, 2010).

Para possibilitar a sistematização dos dados, as disciplinas que compõem as Matrizes Curriculares dos cursos de Geografia, as ART's, as atribuições legais (Lei 6.664/79) e as habilidades e competências (DCN's/2001), foram agrupadas em macro áreas.

O agrupamento observou as nomenclaturas empregadas na caracterização das atribuições legais, competências e disciplinas e, as áreas de concentração da Geografia: Física, Humana e Instrumental (CORREA, 2011; GODOY, 2011; ROSA, 2005; SUERTEGARAY; NUNES, 2001).

Desta forma, por exemplo, a atribuição legal de realizar mapeamentos, a competência para elaborar mapas temáticos, a ART de levantamentos topográficos e a disciplina de Cartografia Temática, foram agrupadas na macro área de Mapeamento/Geotecnologias.

As disciplinas foram quantificadas em relação à carga horária e, as atribuições legais e competências pontuadas em relação ao número de itens dedicados à temática.

A representação da distribuição espacial dos dados segue os princípios da Semiologia Gráfica (BERTIN, 2011) e utiliza a base cartográfica do INSTITUTO BRASILEIRO DE GEOGRAFIA E ESTATÍSTICA - IBGE (IBGE, 2010), bem como o software ESRI ArcGIS (Licença Acadêmica) versão 10.2.

\section{GEÓGRAFO: EVOLUÇÃO DAS ATRIBUIÇÕES E COMPETÊNCIAS}

Apesar de a Lei 6.664 (BRASIL, 1979) regulamentar o exercício da profissão de geógrafo somente no ano de 1979, a formação e a atuação profissional dos mesmos já se fazia presente no Brasil em períodos anteriores. Desta forma, a regulamentação e reconhecimento das atribuições profissionais são derivados da estrutura dos cursos de graduação em Geografia que já atuavam no País, de suas influências históricas e das ações desenvolvidas junto à sociedade pelos profissionais formados em geografia e em áreas correlatas.

Até o ano de 1996, os cursos de graduação no Brasil baseavam sua grade curricular na estrutura denominada de "currículo mínimo". De acordo com este modelo, todos os cursos de graduação deveriam ofertar um leque comum de disciplinas, as quais garantiriam a formação e aquisição das competências relativas à área de atuação (LISBOA; BARBOSA, 2009).

A partir de 1996, o Ministério da Educação, órgão responsável pela implantação da política nacional de educação, passou a se 


\section{EXERCÍCIO PROFISSIONAL DO GEÓGRAFO NO ESTADO DO PARANÁ: CONVERGÊNCIAS E DIVERGÊNCIAS ENTRE A LEI DO GEÓGRAFO, AS DIRETRIZES CURRICULARES NACIONAIS, AS MATRIZES CURRICULARES E A PRÁTICA PROFISSIONAL}

orientar pela Lei 9.394/96 - Lei de Diretrizes e Bases - LDB (BRASIL, 1996), dando início ao processo de reformulação das diretrizes curriculares nacionais para os cursos de graduação.

O novo modelo de educação implementado pela LDB rompeu com a estrutura de formação baseada no currículo mínimo, a partir do pressuposto de que o processo de aprendizagem e aquisição de competências não é estanque, linear e único para todos os indivíduos. Este novo modelo extinguiu a relação disciplina cursada = competência profissional adquirida, passando a estruturar os cursos de graduação a partir de habilidades e competências.

As habilidades e competências podem ser entendidas dentro de diferentes contextos, sendo difícil diferenciar a área de circunscrição destes conceitos. Macedo (2009) aborda as habilidades como competências de ordem particulares necessárias à execução de uma tarefa de âmbito geral, e o saber fazer (agregação de habilidades) à competência propriamente dita (MACEDO, 2009).

O desenvolvimento das habilidades e a aquisição das competências decorrem, portanto, dos Projetos Políticos Pedagógicos (PPP's) dos cursos de graduação, os quais podem apresentar diferenças de região para região e de projeto para projeto.

As matrizes curriculares definidas pelos PPP's passam a ser estruturadas em núcleos (específico, básico, complementar e livre) e, em atividades acadêmicas curriculares. As atividades acadêmicas curriculares contemplam as tradicionais disciplinas e outras atividades que contribuem para a formação profissional. Nesta podem ser incorporadas práticas, como por exemplo, o estágio e a realização de atividades culturais e de extensão (BRASIL, 2003).

Dentre os problemas relativos aos currículos mínimos e, que foram relacionados pelo Parecer CNE/CES 67/2003 (BRASIL, 2003), destacam-se $\mathrm{O}$ engessamento das matrizes curriculares (referida como Grade Curricular), a inibição da inovação e da criatividade e, a prevalência de interesses corporativos responsáveis por obstáculos no ingresso no mercado de trabalho e pela desnecessária ampliação ou prorrogação na duração dos cursos.

De forma contrária, as Diretrizes Curriculares Nacionais concebem a formação como um processo contínuo, autônomo e permanente, que visa garantir uma sólida formação básica e profissional, ao mesmo tempo em que fornece aos alunos uma progressiva autonomia profissional e intelectual. Para tanto, esta formação deve ser adaptável às novas e emergentes demandas sociais e avanços científicos e tecnológicos, o que exige flexibilização curricular e liberdade das instituições para a elaboração de seus projetos pedagógicos (BRASIL, 2003).

Neste contexto, as diretrizes curriculares nacionais para os cursos de Geografia, elaboradas entre 1997 e 1998, objetivaram atender às expectativas apresentadas pela Lei de Diretrizes e Bases da Educação Brasileira - LDB (BRASIL, 1996). Conforme consta na primeira versão publicada, sua elaboração contou com a colaboração de 27 Instituições de Ensino Superior e de membros do CREA (RJ) e, com contribuições, críticas e considerações da AGB (Associação dos Geógrafos do Brasil), CREA (RS) e da presidência do CONFEA (Conselho Federal de Engenharia e Agronomia).

As Diretrizes Curriculares Nacionais publicadas em 1998 e republicadas em 1999 e 2001 (BRASIL, 2001) buscaram reafirmar as atribuições previstas na Lei do Geógrafo, e propuseram $2400 \mathrm{~h}$ como sendo um referencial de carga horária mínima necessária para integralização da formação.

As diretrizes curriculares para os cursos de geografia apresentaram como principais inovações a concepção de formação docente não inferior à dos bacharéis, e, a flexibilidade da formação, como por exemplo, a partir da introdução de um núcleo livre, aonde parte da formação é definida pelo próprio egresso (BRASIL, 2001). 


\section{EXERCÍCIO PROFISSIONAL DO GEÓGRAFO NO ESTADO DO PARANÁ: CONVERGÊNCIAS E DIVERGÊNCIAS ENTRE A LEI DO GEÓGRAFO, AS DIRETRIZES CURRICULARES NACIONAIS, AS MATRIZES CURRICULARES E A PRÁTICA PROFISSIONAL}

Diferente da Lei 6.664/79, as Diretrizes Curriculares Nacionais não apresentaram uma relação de atribuições profissionais, mas sim competências. Estas são, por sua vez, resultado do desenvolvimento de determinadas habilidades, que no caso da Geografia, reproduzem basicamente os mesmos itens previstos na Lei do Geógrafo, garantindo a plena atuação profissional.

As diretrizes curriculares nacionais para os cursos de geografia assumiram como modelo de formação a figura do "professor-geógrafo", o qual entende que os professores devem possuir sólida formação na área da geografia, não inferior à dos bacharéis.

O objetivo desta formação fortalecida e integralizada é garantir que o exercício da docência reflita em sala de aula as áreas de atuação e práticas profissionais dos geógrafos, evitando-se a "cultura da cartilha" (BRASIL, 2001).

As diretrizes curriculares para os cursos de geografia assumiram o pressuposto de que os docentes deveriam ser profissionais com plena e sólida formação na área de atuação dos bacharéis. De acordo com as diretrizes, a formação do docente demanda, além dos conteúdos básicos necessários ao exercício profissional do geógrafo, novos e complementares conhecimentos, os quais permitem que se faça a transposição e adequação do saber geográfico para a educação básica, o que resultou em uma carga horária maior para os cursos de licenciatura.

\section{RESULTADOS}

4.1. GEÓGRAFO: IDENTIFICAÇÃO E TABULAÇÃO DAS MACRO ÁREAS DE ATUAÇÃO NO ÂMBITO DA LEI 6.664/79

A Lei 6.664/79 (BRASIL, 1979), bem como o Decreto $85.138 / 80$ que regulamenta a profissão (BRASIL, 1980), apresentam as atribuições profissionais a serem desempenhadas no exercício de suas funções. Para efeito de análise, entendimento e quantificação as áreas de atuação previstas na Lei, estas atribuições (Art. 3ㅇ, Inciso I, alíneas de ' $a$ ' a ' $n$ ') foram organizadas neste trabalho em 14 itens e agrupadas inicialmente em três macro áreas: Planejamento Territorial, Análise e Estudos Ambientais e, outros.

Estas macro áreas têm por finalidade caracterizar as áreas de atuação, considerando não só a Lei $6.664 / 79$, mas também as habilidades e competências relacionadas pelas Diretrizes Curriculares Nacionais e, as nomenclaturas empregadas pelas ART's.

De acordo com a Lei 6.664/79, a macro área de Planejamento Territorial é a que agrega o maior número de atribuições profissionais, correspondendo a $50 \%$ das atividades descritas pela Lei. Nesta área, encontram-se relacionadas sete das atividades a serem exercidas pelos geógrafos, conforme alíneas ' $a$ ', 'd', 'g', 'h', 'i', 'j' e ' $n$ '. São elas:

1. Delimitar e caracterizar zonas geoeconômicas para fins de planejamento e organização fisicoespacial;

2. Atuar na elaboração e realização do zoneamento geohumano, com vistas aos planejamentos geral e regional;

3. Elaborar e desenvolver políticas de povoamento, migração interna, imigração e colonização de regiões novas ou, na elaboração e desenvolvimento de políticas de revalorização de regiões de velho povoamento;

4. Elaborar estudos fisicoculturais relativos aos setores geoeconômicos, destinado ao planejamento da produção;

5. Estruturar, ou reestruturar, os sistemas de circulação;

6. Realizar estudos e propor o planejamento das bases físicas e geoeconômicas dos núcleos urbanos e rurais;

7. Propor a divisão administrativa da União, dos Estados, dos Territórios e dos Municípios.

A segunda maior macro área de atribuição profissional é a de Análise e Estudos Ambientais, que corresponde a $36 \%$ das atividades relacionadas pela Lei. Tanto a Lei 


\section{EXERCÍCIO PROFISSIONAL DO GEÓGRAFO NO ESTADO DO PARANÁ: CONVERGÊNCIAS E DIVERGÊNCIAS ENTRE A LEI DO GEÓGRAFO, AS DIRETRIZES CURRICULARES NACIONAIS, AS MATRIZES CURRICULARES E A PRÁTICA PROFISSIONAL}

quanto 0 Decreto apresentam as atividades relativas a esta área nas alíneas ' $a$ ', 'b', ' $c$ ', ' $f$ ' e 'l', sendo de competência dos Geógrafos:

1. Delimitar e caracterizar as regiões e subregiões naturais para fins de planejamento e organização fisicoespacial;

2. Propor o equacionamento e a solução, em escala nacional, regional ou local, de problemas atinentes aos recursos naturais do País;

3. Realizar a caracterização ecológica e etológica da paisagem e dos problemas conexos;

4. Realizar a interpretação das condições hidrológicas das bacias fluviais;

5. Propor o aproveitamento, desenvolvimento e preservação dos recursos naturais.

Outras duas atribuições são relacionadas pela Lei e pelo Decreto, conforme alíneas 'e' e ' $m$ '. A primeira se refere à realização de "pesquisas de mercado e intercâmbio comercial em escala regional e inter-regional" (alínea e - o que corresponde a $7 \%$ das atribuições) e, a segunda, diz respeito à realização de "levantamentos e mapeamentos destinados à solução dos problemas regionais" (alínea 'm' - o que também corresponde a $7 \%$ das atribuições).

Desta forma, de acordo com a Lei do Geógrafo o grande campo de atuação do mesmo se encontra nas macro áreas de Planejamento territorial (sete dos 14 itens) e, Análise Ambiental (cinco dos 14 itens). Segundo a Lei, estes dois campos de atuação somados correspondem a $86 \%$ das atividades correlatas à profissão.

\section{2 - GEÓGRAFO: IDENTIFICAÇÃO E TABULAÇÃO DAS MACRO ÁREAS DE ATUAÇÃO NO ÂMBITO DAS DCN'S}

No que se refere às Diretrizes Curriculares Nacionais, Parecer CNE/CES 492 de 2001 (BRASIL, 2001), as atribuições previstas na Lei do Geógrafo foram respeitadas, estando estas indicadas tanto como habilidades como competências relativas à formação básica, contudo, sem fazer distinção entre bacharéis e docentes.
Dezesseis habilidades e dezenove competências foram relacionadas pelas DCN's, de forma a garantir a formação mínima necessária ao exercício da profissão, conforme atribuições apresentadas pela Lei 6664/79.

No que se refere à análise das habilidades, observa-se que estas são de cunho geral e atendem às demandas relacionadas pela Lei, porém, não seguindo a mesma proporcionalidade das macro áreas de atuação apresentadas pela Lei do Geógrafo.

As habilidades relacionadas pelas DCN's fornecem as bases comuns e necessárias à formação tanto dos licenciados como dos bacharéis. Em função das habilidades relacionadas, é possível identificar quatro macro áreas, sendo que duas já se encontravam presentes na Lei (Planejamento Territorial e Análise Ambiental). É a partir dos itens relacionados como habilidades pelas DCN's que se torna possível identificar questões relativas aos "levantamentos e mapeamentos" como sendo uma macro área: Mapeamento/Geotecnologias. As questões relativas às "pesquisas de mercado e intercâmbio comercial em escala regional e inter-regional", previstas como atribuição pela Lei $6.664 / 79$, não foram abordadas enquanto habilidades ou competências pelas DCN's.

As habilidades descritas pelas DCN's possibilitam ainda, a identificação de uma nova macro área relativa ao Ensino. Nesta, geógrafos podem, por exemplo, atuar ofertando cursos de capacitação nas áreas de Geotecnologias, Meio Ambiente e Educação propriamente dita. A tabulação dos itens relativos às habilidades resulta nas seguintes proporções: Análise Ambiental (37\%), Planejamento Territorial (26\%), Mapeamento/Geotecnologias (21\%) e Ensino (16\%).

Por sua vez, as competências previstas pelas DCN's mantiveram as macro áreas já identificadas pela Lei 6.664/79 e permitiram a identificação de mais uma macro área, relativa ao Turismo. A tabulação das competências relacionadas pelas DCN's mostra que as mesmas 


\section{EXERCÍCIO PROFISSIONAL DO GEÓGRAFO NO ESTADO DO PARANÁ: CONVERGÊNCIAS E DIVERGÊNCIAS ENTRE A LEI DO GEÓGRAFO, AS DIRETRIZES CURRICULARES NACIONAIS, AS MATRIZES CURRICULARES E A PRÁTICA PROFISSIONAL}

apresentam maior ênfase na área de Análise Ambiental, que passou a responder por $32 \%$ das competências dos geógrafos. Levantamentos e mapeamentos ganharam ênfase com as DCN's, passando a ocupar o segundo lugar enquanto macro área (nominadas neste trabalho como Mapeamento/Geotecnologias - $26 \%$ das competências).

Planejamento Territorial passou a ocupar o terceiro lugar enquanto macro área, correspondendo a $21 \%$ das competências. As áreas de Ensino/Pesquisa e Turismo apareceram nas DCN's como macro áreas de competência também para os geógrafos, correspondendo a $16 \%$ e $5 \%$ das funções relativas à profissão.

Nota-se que as maiores contribuições trazidas pelas DCN's, foram em relação à ampliação, atualização e detalhamento das áreas de atuação previstas pela Lei 6.664/79, bem como, pela inclusão de áreas de atuação dos geógrafos não previstas pela Lei, como por exemplo: pesquisa, educação ambiental e geotecnologias.

As competências apresentadas pelas DCN's são similares aos itens apresentados pela Lei 6664/79, porém, ainda mais abrangentes que estas e que as habilidades, fornecendo um caráter atual e consonante com as pesquisas e ações relativas aos geógrafos, docentes e pesquisadores formados em Geografia.

Das 19 competências relacionadas pelas DCN's, a macro área de Análise Ambiental (32\% das atribuições), congrega as seguintes competências:

1. Avaliar a utilização dos recursos naturais, bem como os impactos ambientais decorrentes de seu uso e manejo;

2. Propor, planejar, executar e coordenar projetos e programas ambientais;

3. Propor e coordenar políticas ambientais;

4. Propor medidas de contenção, correção ou controle da degradação ambiental;

5. Assessorar órgãos, empresas e instituições na elaboração e implementação de políticas e projetos ambientais e/ou territoriais;
6. Analisar e interpretar as condições hidrológicas das bacias fluviais.

A área de Mapeamento/Geotecnologias (26\%) envolve competências que vão desde a elaboração de gráficos à realização de atividades ligadas ao cadastro urbano e rural. De acordo com as DCN's são competências dos egressos dos cursos de Geografia:

1. Planejar a utilização de uma linguagem científica na solução de um problema geográfico;

2. Avaliar representações ou tratamentos gráficos e matemático-estatísticos;

3. Elaborar mapas temáticos e outras representações gráficas;

4. Elaborar mapeamentos geohumanos, com vista ao planejamento geral e regional;

5. Desenvolver/executar atividades ligadas ao cadastro urbano e rural;

Segundo as DCN's, o Planejamento Territorial passa a corresponder a $21 \%$ das atribuições profissionais (contra $50 \%$ previsto pela Lei do Geógrafo), agregando atividades como:

1. Delimitar e caracterizar regiões e subregiões geográficas naturais e zonas geoeconômicas, para fins de planejamento e organização físico-espacial;

2. Analisar e elaborar estudos e planejamento das bases físicas e geoeconômicas das áreas urbanas, agrárias e regionais;

3. Realizar estudos da estruturação ou reestruturação dos sistemas de circulação viária, de transportes e de revitalização de áreas centrais urbanas;

4. Delimitar a divisão administrativa da União, dos Estados, dos Territórios e Municípios;

As DCN's apresentam as atividades relativas ao Ensino/Pesquisa como competências profissionais que se aplicam também aos geógrafos. Nesta macro área de atuação (16\% das competências) relacionam-se atividades como:

1. Desenvolver investigações científicas sobre os aspectos socioeconômicos, políticos e ambientais e os processos deles resultantes; 
2. Exercer atividades de docência, coordenação de projetos e consultorias na área de educação geográfica;

3. Aplicar metodologia científica na realização de atividades de planejar, executar e avaliar o processo de ensino e aprendizagem.

As atividades ligadas ao Turismo como: a proposição, o planejamento e a execução de projetos, compõem a última grande macro área de competências relacionadas pelas DCN's, correspondendo a $5 \%$ das atividades que podem ser desenvolvidas pelos geógrafos.

As áreas de atuação relacionadas pelas atribuições legais (Lei 6.664/79), habilidades e competências ( $D C N^{\prime}$ 's) são demonstradas pela figura 01.

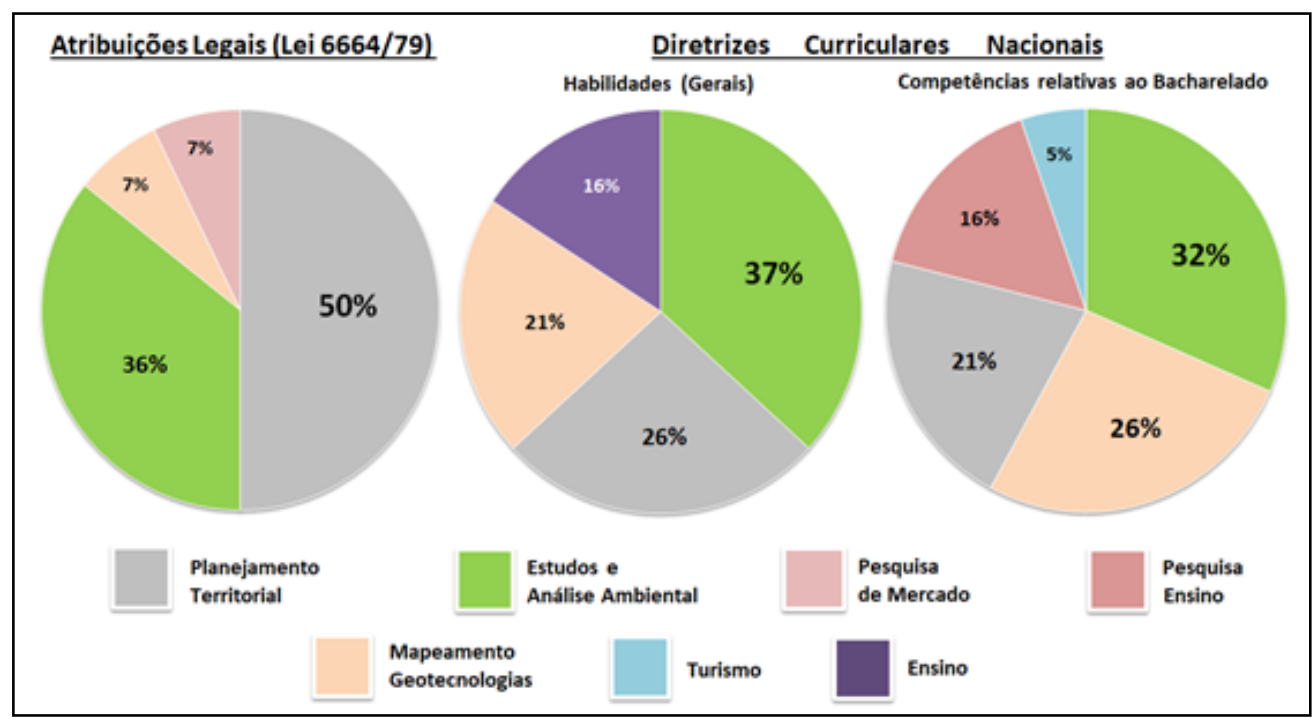

Figura 01 - Análise das áreas de atribuições do Geógrafo, de acordo com Lei 6.664/79, e habilidades e competências do profissional segundo as DCN's.

A figura 02 mostra uma mudança no enfoque da profissão, com redução na proporcionalidade de atribuições na macro área de Planejamento Territorial e simultânea ênfase ao Mapeamento/Geotecnologias. Esta mudança não significa redução no número de atribuições previstas pela Lei, mas se deve à maior ênfase e detalhamento das competências relativas ao Mapeamento/Geotecnologias.

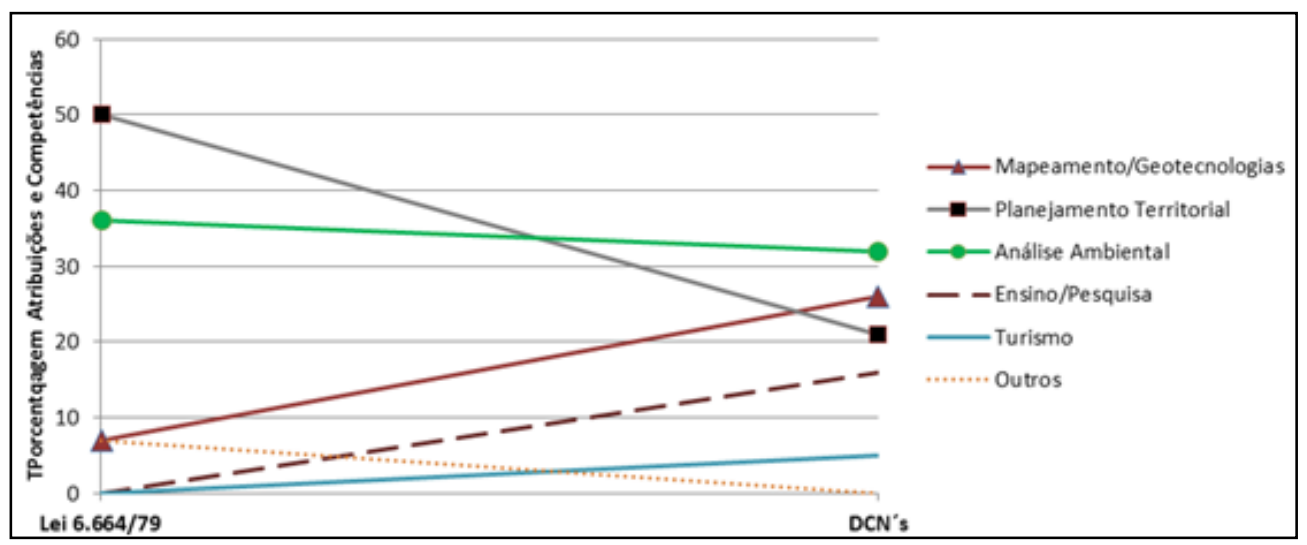

Figura 02 - Mudança na proporcionalidade de atribuições e competências profissional (Lei 6.664/79 e DCN's). 
As DCN's mantêm as atribuições previstas pela Lei, mas detalham e introduzem novas competências profissionais, ampliando o leque de atividades profissionais, em especial nas áreas de Ensino/Pesquisa e Turismo.

Cabe ressaltar que a atividade de docência em nível superior e pesquisa, tanto em Instituições de Ensino Superior como em Institutos de Pesquisas (ex.: Empresa Brasileira de Pesquisa Agropecuária - EMBRAPA, Instituto Brasileiro de Geografia e Estatística - IBGE e outros) são atribuições profissionais e, também devem apresentar anotação de responsabilidade técnica (ART).

\subsection{FORMAÇÃO E ATUAÇÃO DOS GEÓGRAFOS NO PARANÁ: DISTRIBUIÇÃO DOS PROFISSIONAIS E DAS ART'S}

No estado do Paraná existem oito cursos de Bacharelado em Geografia, localizados nos municípios de Curitiba, Ponta Grossa, Guarapuava, Londrina, Maringá, Campo Mourão, Francisco Beltrão e Foz do Iguaçu. Segundo dados fornecidos pelo CREA-PR, em 2015 existiam 393 Profissionais com registros ativos no Estado. A figura 03 apresenta quantidade e a distribuição espacial dos Geógrafos no Paraná.

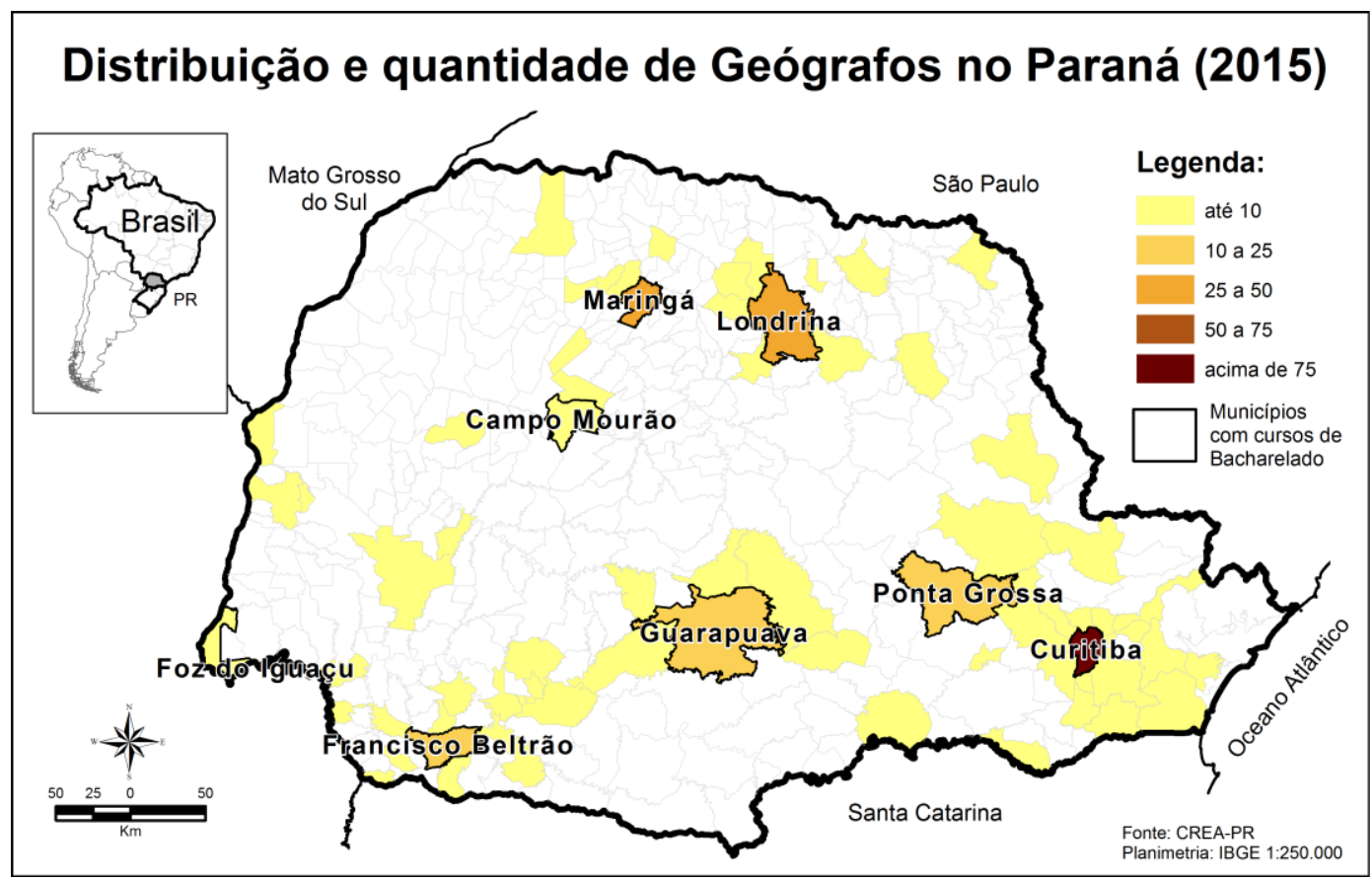

Figura 03 - Distribuição Espacial dos Cursos de Bacharelado em Geografia e dos Geógrafos no Estado do Paraná. Fonte: CREA-PR (2015), organizado pelos autores (2016).

No período de 2011 a 2015 foram recolhidas 6.660 ART's por Geógrafos no Paraná, o que resulta em uma média de 1332 ART's/ano. As ART's recolhidas não se deram apenas nos municípios que possuem Geógrafos registrados, mas se distribuem por praticamente todo o Estado (Figura 04).
Regiões centro-norte e oeste do Estado apresentam maior número de municípios sem o registro de recolhimento de $\mathrm{ART}^{\prime} \mathrm{s}$. Estas áreas representam, a princípio, potenciais áreas de atuação. $O$ mesmo pode ser dito em relação às áreas central e centro-sul, nas quais o número de ART's indica baixa atuação profissional. 


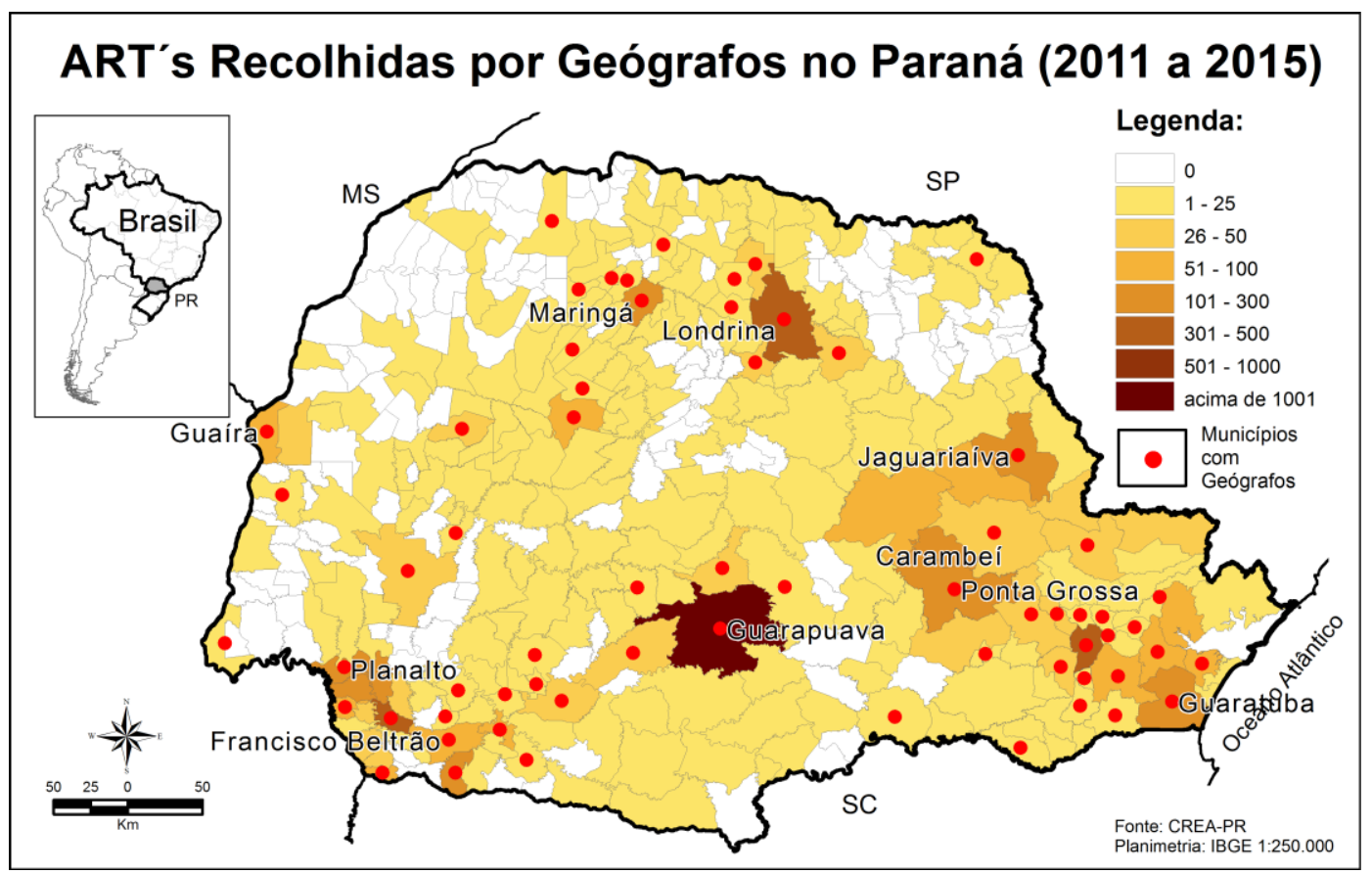

Figura 04 - ART's recolhidas e municípios com geógrafos no estado do Paraná. Fonte: CREA-PR (2015), organizado pelos autores (2016).

Esta quantidade de ART's indica uma produtividade média de aproximadamente 3,4 ART's por profissional por ano. Porém, quando se analisa a produtividade dos Geógrafos por município (divisão do número de ART's pelo número de profissionais registrados), se observa que a produtividade não segue a densidade de profissionais dos municípios (Figura 05).

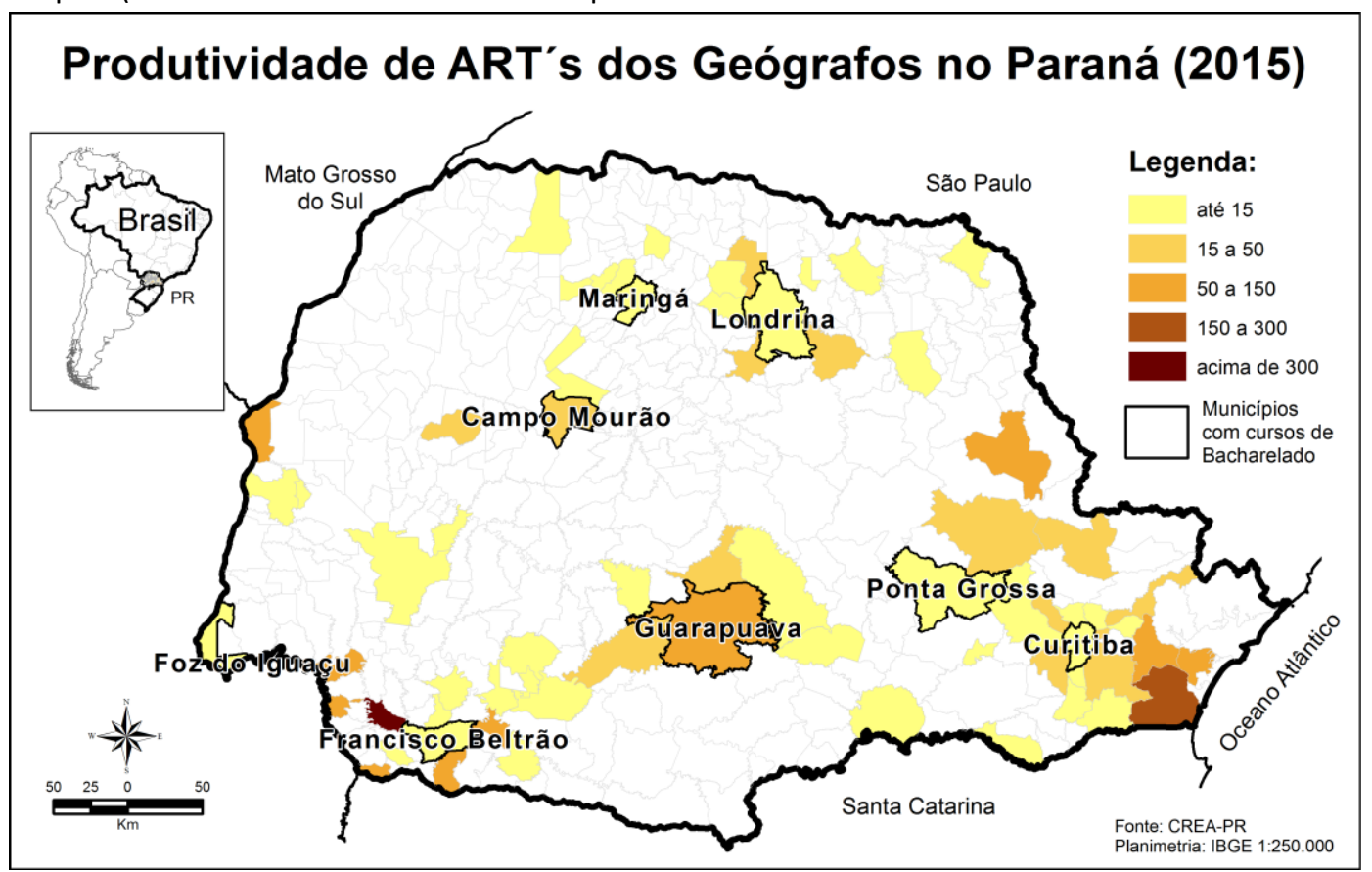

Figura 05 - Produtividade de ART's no estado do Paraná. Fonte: CREA-PR (2015), organizado pelos autores (2016). 


\section{EXERCÍCIO PROFISSIONAL DO GEÓGRAFO NO ESTADO DO PARANÁ: CONVERGÊNCIAS E DIVERGÊNCIAS ENTRE A LEI DO GEÓGRAFO, AS DIRETRIZES CURRICULARES NACIONAIS, AS MATRIZES CURRICULARES E A PRÁTICA PROFISSIONAL}

Ganha destaque neste cenário os
municípios de Ampére (vizinho a Francisco
Beltrão) e Guaratuba (no litoral do Paraná), pois
os mesmos possuem apenas um profissional
registrado e, nestes municípios foram recolhidas
no período de análise 467 e 242 ART's,
respectivamente.
O município com o maior número de ART's recolhidas é Guarapuava, com 1228 ART's entre 2011 e 2015. Contudo, Guarapuava apesar possuir a oferta do Bacharelado possui apenas 23 Geógrafos registrados, o que fornece ao mesmo uma produtividade de 53,4 ART's por Geógrafo/ano em média.

Dos outros sete municípios em que há oferta de cursos de Bacharelado, seis encontramse acima da média de ART's recolhidas por geógrafos no Estado. Campo Mourão, com cinco Geógrafos e 78 ART's (15,6 ART's/Geógrafo); Ponta Grossa, com 21 Geógrafos e 177 ART's $(8,4$ ART's Geógrafo); Londrina, com 45 Geógrafos e 302 ART's (6,7 ART's/Geógrafo); Maringá, com 41 Geógrafos e 259 ART's (6,3 ART's/Geógrafo), Francisco Beltrão, com 15 Geógrafos e 67 ART's (4,5 ART's/Geógrafo) e Foz do Iguaçu, com três Geógrafos e 11 ART's (3,6 ART's Geógrafo).

Curitiba com 155 Geógrafos registrou no mesmo período 423 ART's (2,7 ART's/Geógrafo), com produtividade abaixo da média do Estado. Este fato pode estar associado à distribuição dos profissionais e ART's pela Região Metropolitana de Curitiba, na qual municípios como Araucária (20,5 ART's/Geógrafo), Campo Magro (20,5 ART's/Geógrafo), Campina Grande do Sul (18 ART's/Geógrafo), São José dos Pinhais $(16,5$ ART's/Geógrafo), Colombo (12,5 ART's/Geógrafo) e Almirante Tamandaré (11,5 ART's/Geógrafo), dentre outros, apresentam produtividade acima da média. Ainda, a baixa produtividade de Curitiba pode estar associada também à ocorrência de registros ativos junto ao CREA, porém de profissionais já aposentados, uma vez que se trata do mais antigo curso de Bacharelado do Estado.
Municípios como Capanema, Jaguaraíva, Pérola D'Oeste, Itapejara D'Oeste, Guaíra, Morretes, Paranaguá, Barracão e Castro, apesar de possuir apenas um Geógrafo registrado, apresentam produtividade acima de 50 ART's por profissional. Marmeleiro é outro município que se destaca, uma vez que possui apenas dois Geógrafos registrados e apresentou produtividade de 62,5 ART's por Geógrafo/ano no período analisado.

Cabe destacar que, possivelmente, Geógrafos registrados no CREA-PR tenham recolhido ART's em outros estados durante este período, contudo as mesmas não foram tabuladas por esta pesquisa, bem como deve ser levado em consideração o fato de que é comum que um determinado geógrafo atue também em outros municípios do Estado do Paraná, além daquele no qual está registrado.

Há também que se destacar o fato de que há geógrafos atuando como autônomos e, portanto recolhendo ART's em seu nome; contudo há geógrafos atuando em projetos de outras empresas, onde muitas vezes as ART's são recolhidas apenas no nome dos sócios, visando incrementar o Acervo Técnico para possibilitar a participação das empresas em concorrências públicas.

\section{4 - FORMAÇÃO E ATUAÇÃO DOS GEÓGRAFOS NO PARANÁ: TIPOLOGIA E MACRO ÁREAS DAS ART'S}

No que se refere ao número de ART's recolhidas, observa-se que houve crescimento no período analisado (2011 a 2015), com queda no ano de 2014. Este fato pode estar associado à redução no número de investimentos do Setor Público (responsável pela maior parte dos investimentos em planejamento territorial, análise ambiental e mapeamento) e à retração da economia no período, tanto nacional como estadual (Figura 06). 


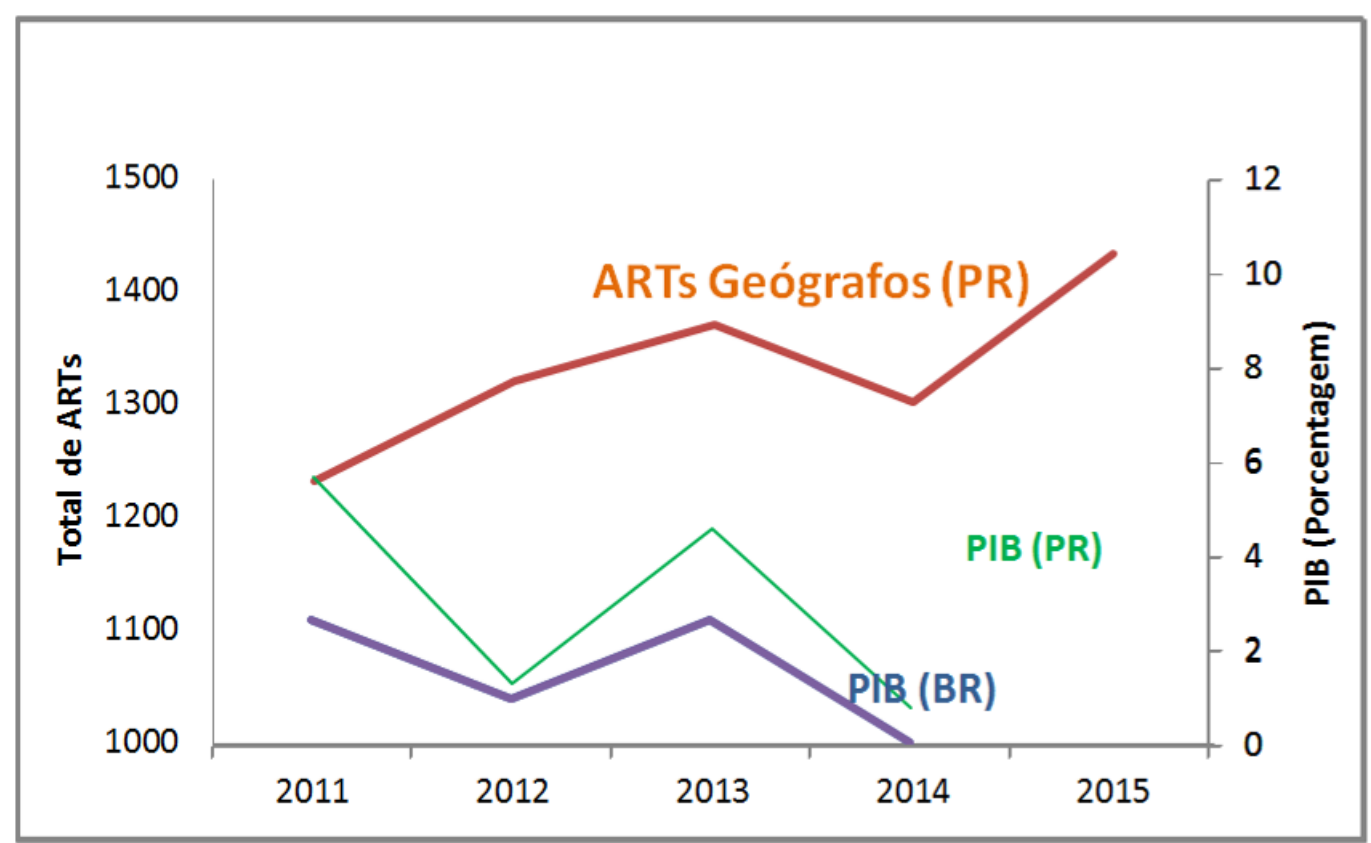

Figura 06 - Recolhimento de ART's no Paraná no período de 2011 a 2015, comparação com PIB Nacional e Paranaense 2011 a 2014 (Fonte IPARDES/IBGE). Os dados do PIB do estado do Paraná referentes ao ano de 2015 não foram divulgados pelo IBGE até a presente data. FONTES: IPARDES; IBGE; CREA-PR (2015), organizado pelos autores (2016).

A análise do total de ART's recolhidas no Estado, desde o início de sua obrigatoriedade até o ano de 2015, revela uma grande diversidade de temas, sendo alguns nitidamente divergentes das atribuições, habilidades e competências relativas à profissão (Lei e DCN's). Parte das ART's recolhidas não condiz com as atribuições e competências relacionadas e, sequer podem ser enquadradas no contexto das macro áreas. São exemplo, as ART's de Projeto de Interiores, Floricultura, Receituário Agronômico, Sistema de Iluminação, Sistema de Sonorização, Radiodifusão, Piscina, etc. Estas ART's totalizam 3389 registros, o que corresponde a 23,3\% de todas as ART's recolhidas no Estado.

Apesar de existir no sistema de registro de ART's dos CREA's alguns dos códigos facilmente identificáveis como sendo relativos ao exercício profissional dos geógrafos, como por exemplo: Equacionamento de problemas referentes aos recursos naturais (4634) e, Zoneamento Geohumano (1665), nem sempre as atividades desenvolvidas se enquadram de forma adequada nos códigos disponíveis, o que pode contribuir para o elevado número de ART's registradas em áreas não afins às atribuições, competências e macro áreas de atuação.

Considerando somente as ART's relativas aos campos de atuação previstos na Lei ou relacionadas como competências dos geógrafos pelas $D C N$ 's, se observa que entre os 10 itens de maior porcentagem de recolhimento de ART's, nove são relativos à macro área de Mapeamento/Geotecnologias (Tab. 1). 


\section{EXERCÍCIO PROFISSIONAL DO GEÓGRAFO NO ESTADO DO PARANÁ: CONVERGÊNCIAS E DIVERGÊNCIAS ENTRE A LEI DO GEÓGRAFO, AS DIRETRIZES CURRICULARES NACIONAIS, AS MATRIZES CURRICULARES E A PRÁTICA PROFISSIONAL}

Tabela 01 - Ranking das principais atividades desenvolvidas pelos Geógrafos no Paraná a partir da análise da quantidade e porcentagem de ART recolhidas (total até 2015).

\begin{tabular}{|c|c|c|c|c|}
\hline Ranking & Tipo de Obra & ART's (Qtd) & Porcentagem & Macro área \\
\hline 1 & LEVANTAMENTOS TOPOGRÁFICOS & 2353 & $21,2 \%$ & Mapeamento/Geotecnologias \\
\hline 2 & OUTRAS ATIVIDADES AGRIM/TOP/CART/GEOD/GEOGR & 1699 & $15,3 \%$ & Mapeamento/Geotecnologias \\
\hline 3 & SUBDIVISÃO DE ÁREAS - ÁREA URBANA & 1463 & $13,2 \%$ & Mapeamento/Geotecnologias \\
\hline 4 & SUBDIVISÃO DE ÁREAS & 674 & $6,1 \%$ & Mapeamento/Geotecnologias \\
\hline 5 & LEVANTAMENTOS TOPOGRÁFICOS-ÁREA RURAL & 627 & $5,6 \%$ & Mapeamento/Geotecnologias \\
\hline 6 & LEVANTAMENTOS TOPOGRÁFICOS - ÁREA URBANA & 611 & $5,5 \%$ & Mapeamento/Geotecnologias \\
\hline 7 & OUTRAS OBRAS/SERVIÇOS MOD AGRIMENSURA-CARTOGRAFIA & 513 & $4,6 \%$ & Mapeamento/Geotecnologias \\
\hline 8 & RESERVA LEGAL E ÁREAS DE PRESERVAÇÃO PERMANENTE & 497 & $4,5 \%$ & Mapeamento/Geotecnologias \\
\hline 9 & APROVEITAMENTO/DESENV/PRESERVAÇÃO DE REC.NATURAIS & 395 & $3,6 \%$ & Análise Ambiental \\
\hline 10 & SUBDIVISÃO DE ÁREAS - ÁREA RURAL & 344 & $3,1 \%$ & Mapeamento/Geotecnologias \\
\hline 11 & UNIFICAÇÃO DE ÁREAS - ÁREA URBANA & 302 & $2,7 \%$ & Mapeamento/Geotecnologias \\
\hline 12 & LAUDOS, AVALIAÇÕ̃ES, VISTORIAS E PERÍCIAS & 205 & $1,8 \%$ & Perícia \\
\hline 13 & DESEMPENHO CARGO/FUNÇÃO & 174 & $1,6 \%$ & Funções Administrativas \\
\hline 14 & EQUACIONAMENTO DE PROBLEMAS REF A REC. NATURAIS & 168 & $1,5 \%$ & Análise Ambiental \\
\hline 15 & ESTUDO/PLANEJ DE BASES DE NÚCLEOS URBANOS E RURAIS & 159 & $1,4 \%$ & Planejamento Territorial \\
\hline 16 & UNIFICAÇÃO DE ÁREAS & 155 & $1,4 \%$ & Mapeamento/Geotecnologias \\
\hline 17 & LOTEAMENTOS & 142 & $1,3 \%$ & Mapeamento/Geotecnologias \\
\hline 18 & LOCAÇÃO/DEMARCAÇÃO DE LOTES E QUADRAS & 127 & $1,1 \%$ & Mapeamento/Geotecnologias \\
\hline 19 & CARACT ECOLÓGICA/ETOLÓGICA PAISAGEM GEOGRÁFICA & 122 & $1,1 \%$ & Análise Ambiental \\
\hline 20 & AGRICULTURA FAMILIAR - PRONAF & 87 & $0,8 \%$ & Planejamento Territorial \\
\hline 21 & DELIMITAÇÃO/CARACTERIZAÇÃO DE REGIỖES E SUB-REGIỖES & 49 & $0,4 \%$ & Planejamento Territorial \\
\hline 22 & LEVANTAMENTOS GEODÉSICOS & 39 & $0,4 \%$ & Mapeamento/Geotecnologias \\
\hline 23 & UNIFICAÇÃO DE ÁREAS - ÁREA RURAL & 39 & $0,4 \%$ & Mapeamento/Geotecnologias \\
\hline 24 & LEVANTAMENTO/MAPEAMENTO REF PROBLEMAS REGIONAIS & 36 & $0,3 \%$ & Mapeamento/Geotecnologias \\
\hline 25 & ESTUDO FÍSICO-CULTURAL DE SETORES GEOECONÔMICOS & 33 & $0,3 \%$ & Planejamento Territorial \\
\hline 26 & INTERPRETAÇÃO CONDIÇÕES HIDROLÓGICAS DE BACIAS FLUVIAIS & 24 & $0,2 \%$ & Análise Ambiental \\
\hline 27 & ZONEAMENTO GEO-HUMANO & 20 & $0,2 \%$ & Planejamento Territorial \\
\hline 28 & LOCAÇÃO DE SISTEMA DE SANEAMENTO & 14 & $0,1 \%$ & Mapeamento/Geotecnologias \\
\hline 29 & ASSISTÊNCIA / ASSESSORIA / CONSULTORIA & 12 & $0,1 \%$ & Consultorias \\
\hline 30 & PESQUISAS DE MERCADO E INTERCÂMBIO COMERCIAL & 9 & $0,1 \%$ & Planejamento Territorial \\
\hline 31 & ESTRUTURAÇÃO DE SISTEMAS DE CIRCULAÇÃO & 9 & $0,1 \%$ & Planejamento Territorial \\
\hline 32 & PLANEJAMENTO FISICO DO TERRENO URBANO, RURAL E REGIONAL & 4 & $0,0 \%$ & Análise Ambiental \\
\hline 33 & ELABORAÇÃO DO RELATÓRIO DE IMPACTO NO MEIO AMBIENTE - RIMA & 1 & $0,0 \%$ & Análise Ambiental \\
\hline 34 & POLÍTICAS DE POVOAMENTO E MIGRAÇÃO INTERNA & 1 & $0,0 \%$ & Planejamento Territorial \\
\hline 35 & DIVISÃO ADMINISTRATIVA DA UNIÃO/ESTADOS/MUNICÍPIOS & 1 & $0,0 \%$ & Planejamento Territorial \\
\hline
\end{tabular}

Fonte: CREA-PR (2015), organizado pelos autores (2016).

Cabe observar, que é possível que tanto no oitavo item do ranking de ART's, quanto no nono, parte das atividades desenvolvidas sejam relativas às macro áreas de Mapeamento/Geotecnologias e de Análise Ambiental. Contudo, em função do não acesso à descrição das atividades (somente foi disponibilizado o código e o nome da atividade) e do conhecimento prévio das atividades desenvolvidas no Estado, estes itens foram classificados e agrupados neste trabalho como sendo: o oitavo item relativo à macro área de Mapeamento/Geotecnologia e, o nono como Análise Ambiental.

A análise das ART's no Paraná revela que a principal macro área de atuação dos geógrafos no Estado é a de Mapeamento/Geotecnologias, respondendo por $86,7 \%$ do total de ART's. Dentre as ART's recolhidas nesta macro área, a topografia está diretamente, ou indiretamente, relacionada à maioria das atividades desenvolvidas pelos geógrafos que apresentam anotação de responsabilidade técnica no CREAPR.

De acordo com o ranking (Figura 07) a segunda maior macro área de atuação corresponde à Análise Ambiental (6,4\%), a terceira é a de Planejamento Territorial (3,3\%), a quarta corresponde à realização de Perícias $(1,8 \%)$, a quinta à Funções administrativas $(1,6 \%)$ e, a sexta à Consultoria $(0,1 \%)$. 


\section{EXERCÍCIO PROFISSIONAL DO GEÓGRAFO NO ESTADO DO PARANÁ: CONVERGÊNCIAS E DIVERGÊNCIAS ENTRE A LEI DO GEÓGRAFO, AS DIRETRIZES CURRICULARES NACIONAIS, AS MATRIZES CURRICULARES E A PRÁTICA PROFISSIONAL}

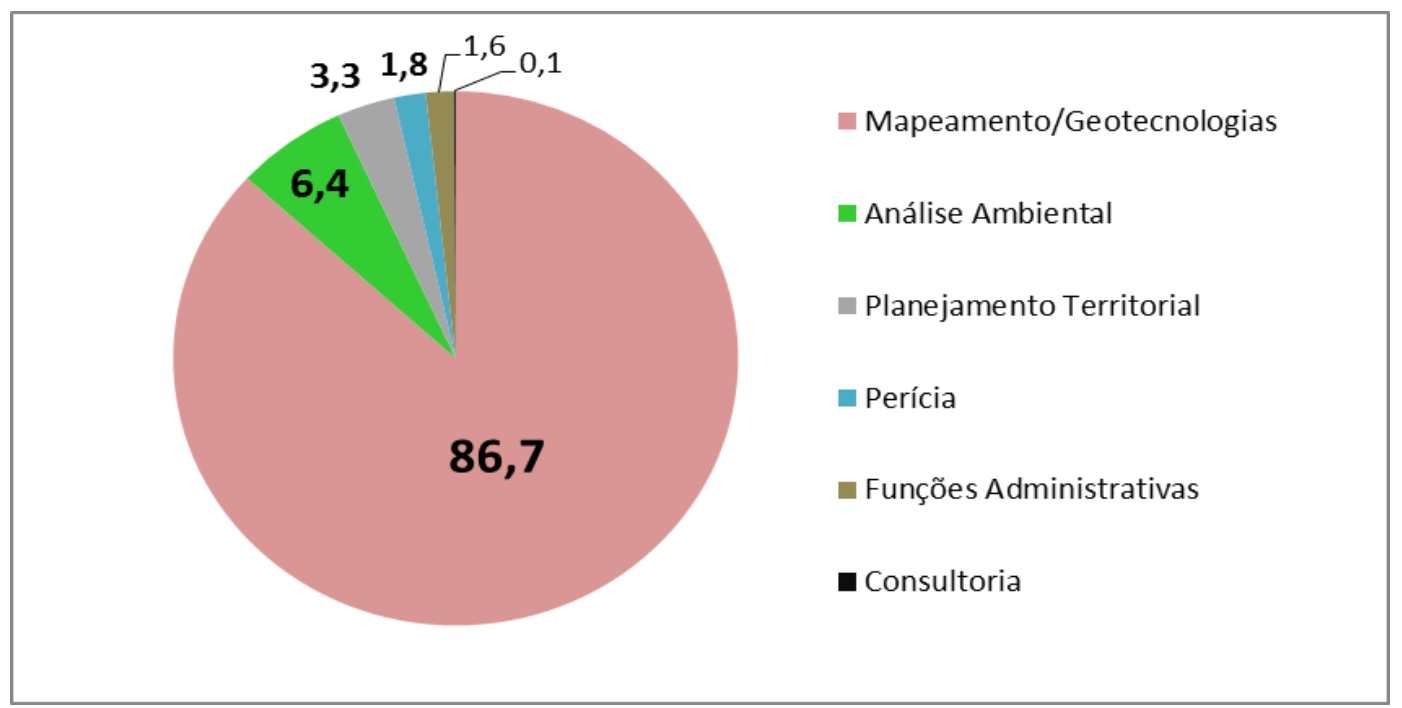

Figura 07 - Hierarquia das macro áreas de atuação dos geógrafos no Paraná, a partir da análise das ART'S recolhidas até o ano de 2015. Fonte: CREA-PR (2015), organizado pelos autores (2016).

Pelo conhecimento informal das atividades desenvolvidas no Estado, é possível inferir que as áreas de Perícia e Consultoria possuam maior relação com a macro área de Análise Ambiental, o que manteria a mesma em segundo lugar no ranking, porém com 8,3\% das atividades. Contudo, em função do não acesso às ART's propriamente ditas, estes itens foram tabulados separadamente.

As ART's que possuem maior relação enquanto denominação, com as funções relativas às atribuições e competências, ocupam posições inferiores no ranking das anotações. Somente a partir da nona posição do ranking é que se registra uma maior afinidade entre as ART's e as atribuições e competências relacionadas pela Lei e pelas DCN's.

Por fim, cabe destacar que não há registro no Estado de anotação técnica relativa às macro áreas de Ensino/Pesquisa, apesar de ser obrigatório o recolhimento de ART's para docentes do Ensino Superior e, de atividades ligadas ao Turismo.

\section{5 - ANÁLISE DAS MATRIZES CURRICULARES DOS CURSOS DE GEOGRAFIA (BACHARELADO) DO PARANÁ}

No estado do Paraná existem oito cursos de Bacharelado em Geografia, localizados nos municípios de Campo Mourão (Universidade Estadual do Paraná - UNESPAR), Curitiba (Universidade Federal do Paraná - UFPR), Foz do Iguaçu (Universidade Federal da Integração Latino-Americana - UNILA), Francisco Beltrão (Universidade Estadual do Oeste do Paraná UNIOESTE), Guarapuava (Universidade Estadual do Centro-Oeste - UNICENTRO), Londrina (Universidade Estadual de Londrina - UEL), Maringá (Universidade Estadual de Maringá UEM) e Ponta Grossa (Universidade Estadual de Ponta Grossa - UFPR).

Sete cursos possuem duração de quatro anos e um de cinco anos (UNESPAR). Este curso (UNESPAR - 4512 horas) possui 1044 horas a mais do que o curso com maior carga horária de quatro anos (UNILA) (Fig. 8) e, 912 horas a mais do que a carga horária de referência para os cursos de engenharia (3600h).

A carga horária média é de 3115 horas para os cursos com duração de quatro anos e, 3289,5 horas a geral. A carga horária dos cursos é, em ordem decrescente: UNESPAR - 4512h, UNILA - 3468h, UEPG - 3294h, UNICENTRO 3208h, UEM - 3164h, UEL - 3000h, UNIOESTE $3000 \mathrm{~h}$ e, UFPR - 2670h. A carga horária do curso de geografia da UFPR é 445 horas inferior a média dos cursos com duração de quatro anos. 


\section{EXERCÍCIO PROFISSIONAL DO GEÓGRAFO NO ESTADO DO PARANÁ: CONVERGÊNCIAS E DIVERGÊNCIAS ENTRE A LEI DO GEÓGRAFO, AS DIRETRIZES CURRICULARES NACIONAIS, AS MATRIZES CURRICULARES E A PRÁTICA PROFISSIONAL}

Chama a atenção neste contexto os extremos dos cursos com quatro anos de duração (UNILA e UFPR), com diferença de 798 horas, o que corresponde em termos práticos a aproximadamente dois semestres letivos.

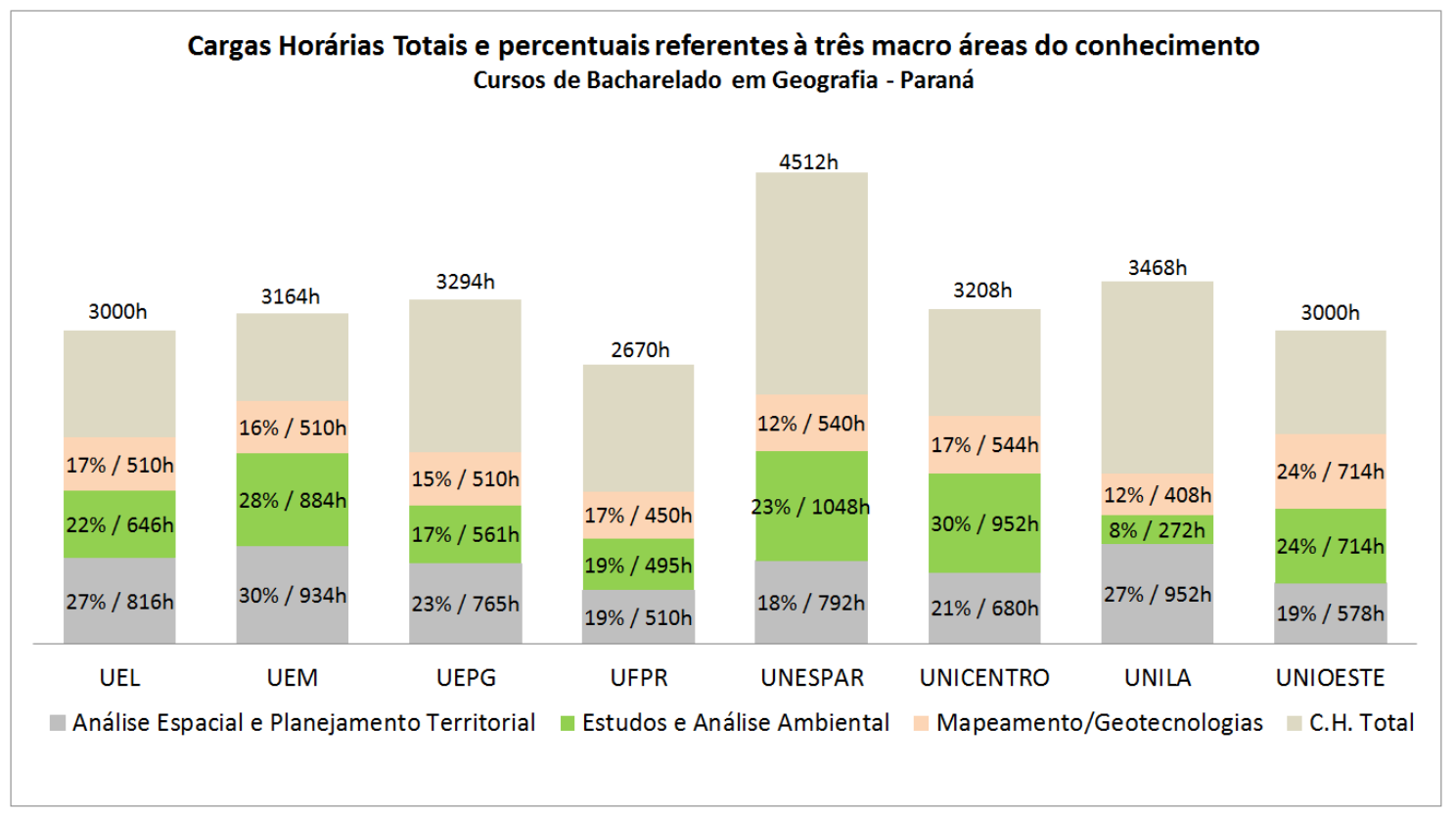

Figura 08 - Cargas horárias totais e percentuais referentes à três macro áreas do conhecimento - cursos de bacharelado em geografia - Paraná. Fonte: Currículos disponibilizados pelas IES, organizado pelos autores (2016).

A despeito das especificidades envolvendo a carga horária total dos cursos, a ênfase que será dada à discussão das matrizes curriculares dos cursos de bacharelado em Geografia no estado do Paraná refere-se à estruturação do currículo, considerando somente as disciplinas obrigatórias, entorno das três macro áreas já identificadas.

A macro área de Estudos e Análise Ambiental representa $36 \%$ das atribuições dos geógrafos previstas em Lei, $37 \%$ das habilidades e $32 \%$ das competências apresentadas pelas DCN's. Os dados demonstram (Fig. 8) que a variação das horas dedicadas a esse tema nos currículos é muito grande, tanto em termos percentuais, quanto em quantidade absoluta de horas.

O curso da UNILA (2 maior em carga horária) destina a menor quantidade de horas para esta macro área, tanto em termos percentuais $(8 \%)$, quanto em valores absolutos (272h). Já o curso da UNICENTRO destina o maior percentual de horas (30\% - 952h) e, o da UNESPAR a maior quantidade de horas efetivas (1048h). Neste sentido, o curso da UNICENTRO é o que melhor se enquadra na perspectiva das proporcionalidades entre as macro áreas proposta pelas DCN's, apesar do curso da UNESPAR apresentar maior número efetivo de horas dedicadas a esta temática.

A discrepância entre as matrizes curriculares fica evidente ao se comparar as matrizes com menor e maior quantidade de horas dedicadas à área de Estudos e Análise Ambiental: 1048h (UNESPAR) e 272h (UNILA).

As disciplinas constantes nas matrizes curriculares inerentes a esse tema e que merecem destaque por se diferenciar das demais são: "Perícia Ambiental" (UNIOESTE), "Hidrologia e Saneamento Ambiental" (UNESPAR), "Hidrogeografia e Geografia Marinha" (UEM), "Recursos Naturais e Análise Ambiental" (UNICENTRO). 


\section{EXERCÍCIO PROFISSIONAL DO GEÓGRAFO NO ESTADO DO PARANÁ: CONVERGÊNCIAS E DIVERGÊNCIAS ENTRE A LEI DO GEÓGRAFO, AS DIRETRIZES CURRICULARES NACIONAIS, AS MATRIZES CURRICULARES E A PRÁTICA PROFISSIONAL}

A macro área de Análise Espacial e Planejamento Territorial, conforme exposto anteriormente, representa $50 \%$ das atribuições dos geógrafos previstas em Lei, $26 \%$ das habilidades e $21 \%$ das competências expostas nas DCN's. Os dados expostos na figura 8 demonstram que os percentuais das matrizes curriculares dedicados a essa macro área convergem com os percentuais propostos pelas DCN's, uma vez que os cursos dedicam entre $18 \%$ e $30 \%$ de sua carga horária para esta área.

Contudo, em termos de carga horária absoluta as diferenças são expressivas, uma vez que o curso da UFPR (menor quantidade de horas dedicadas a esta macro área) dedica $510 \mathrm{~h}$ e, a UNILA, (maior quantidade absoluta) destina 952h.

Nesta macro área merecem destaques disciplinas como: "Redes e Fluxos: Transportes e Comunicações" e "Estratégias e Dinâmicas Territoriais da Indústria" (UNILA), "Plano Diretor Municipal" e "Patrimônio Identitário e Cultural" (UNIOESTE), "Geografia Industrial" (UFPR), Sociologia e Sociedade no Brasil" (UEM), "Demografia" (UEPG) e, "Antropologia Social" (UNESPAR).

$$
\text { A macro área de }
$$

Mapeamento/Geotecnologias $\quad(26 \%$ das competências expostas pelas DCN's) apresenta menor variação na quantidade absoluta de horas, sendo que três cursos dedicam 510h a esta temática (Fig. 8) e, a média dos cursos no Estado é de $523 \mathrm{~h}$.

Os cursos da UNESPAR (10 lugar em carga horária) e da UNILA (2ㅇ) dedicam $12 \%$ de suas matrizes curriculares a esta macro área. Portanto, muito aquém dos percentuais preconizados pelas DCN's. O curso da UNIOESTE (70) é o que mais se aproxima da proposta das DCN's, dedicando a maior quantidade de horas absolutas a esta macro área (714h), o que corresponde a $24 \%$ da carga horária total do curso.

O curso de bacharelado da UNILA é o que apresenta menor quantidade absoluta nesta área (408h), o que corresponde a aproximadamente uma ou duas disciplinas (60h ou 68h) a menos do que a maioria dos demais cursos.

Destacam-se nesta macro área disciplinas como: "Análise de Dados em Geografia e Cartografia" (UNILA), "Matemática Aplicada às Geotecnologias" e "Física Aplicadas às Geotecnologias" (UNIOESTE), "Geoestatística" (UNESPAR e UEPG) e "Introdução à Modelagem em Geografia e Estatística Espacial” (UNICENTRO).

Dos oito cursos analisados, o da UFPR é o único que não contempla nenhuma disciplina obrigatória relacionada à Topografia e Agrimensura, embora a maioria das ART's recolhidas até 2015 envolva direta ou indiretamente Topografia e Agrimensura.

As macro áreas 'Ensino/Pesquisa' e 'Turismo' não foram incluídas na distribuição das cargas horárias das matrizes curriculares (Fig. 8). A macro área de Ensino/Pesquisa possui $60 \mathrm{~h}$ na matriz curricular obrigatória da UFPR; $68 \mathrm{~h}$ na UEL, UNICENTRO, UNILA e UNIOESTE; $164 \mathrm{~h}$ na UEM; 306h na UEPG; e $720 \mathrm{~h}$ na UNESPAR (Tab. 2). 


\section{EXERCÍCIO PROFISSIONAL DO GEÓGRAFO NO ESTADO DO PARANÁ: CONVERGÊNCIAS E DIVERGÊNCIAS ENTRE A LEI DO GEÓGRAFO, AS DIRETRIZES CURRICULARES NACIONAIS, AS MATRIZES CURRICULARES E A PRÁTICA PROFISSIONAL}

Tabela 2 - Distribuição da carga horária da macro área de Ensino e Pesquisa nos oito cursos de bacharelado em Geografia do estado do Paraná.

\begin{tabular}{c|cccccccc}
\hline $\begin{array}{c}\text { Macro área de Ensino e } \\
\text { Pesquisa }\end{array}$ & UEL & UEM & UEPG & UFPR & UNESPAR UNICENTRO & UNILA & UNIOESTE \\
\hline Carga horária & $68 \mathrm{~h}$ & $164 \mathrm{~h}$ & $306 \mathrm{~h}$ & $60 \mathrm{~h}$ & $720 \mathrm{~h}$ & $68 \mathrm{~h}$ & $68 \mathrm{~h}$ & $68 \mathrm{~h}$ \\
\hline $\begin{array}{c}\text { Percentual em relação à } \\
\text { carga horária total do curso }\end{array}$ & $2,3 \%$ & $5,2 \%$ & $9,3 \%$ & $2,2 \%$ & $16,0 \%$ & $2,1 \%$ & $2,0 \%$ & $2,3 \%$ \\
\hline
\end{tabular}

Fonte: Fonte: Currículos disponibilizados pelas IES, organizado pelos autores (2016).

Com exceção da UNILA, todas as demais possuem em seu currículo disciplina obrigatória envolvendo a Metodologia de Pesquisa em Geografia (única disciplina da macro área de Ensino/Pesquisa nos cursos de Geografia da UEL, UFPR, UNICENTRO e UNIOESTE). Nesta macro área o curso da UNESPAR se destaca por apresentar $720 \mathrm{~h}$, o que equivale a $16 \%$ da carga horária total do curso. Dentre as disciplinas ofertadas estão: "Fundamentos Teóricos e Epistemológicos em Educação Ambiental", "Psicologia Educacional", "Políticas Educacionais" e "Metodologias de Ensino de Geografia I e II".

Com exceção do curso da UEL, os demais apresentam parte da formação associada a disciplinas optativas/livres/eletivas (Núcleo Livre - de acordo com as DCN's). As matrizes estabelecem as seguintes quantidades e cargas horárias que devem ser cumpridas em disciplinas optativas/eletivas/livres: UFPR - sete disciplinas (420h), UNILA - seis disciplinas (408h), UNICENTRO - duas disciplinas (204h), UEPG três disciplinas (153h), UEM - três disciplinas (170h), UNIOESTE - duas disciplinas (132h) e UNESPAR - uma disciplina (72h).

No que diz respeito à preparação para a prática profissional do bacharel, os Estágios Obrigatórios apresentam cargas horárias que variam de 142h (UNILA) até 600h (UNESPAR). Merece destaque os cursos que inseriram disciplinas específicas para a atuação do geógrafo como: "Ética, Legislação e Exercício Profissional no Sistema CONFEA/CREA" e "Prática Profissional do Bacharel em Geografia" (UNICENTRO), e "Administração e Prática Profissional” (UEPG).

A análise das matrizes curriculares mostra que os cursos de bacharelado em
Geografia no estado do Paraná não contemplam a macro área de turismo e, a exceção da UNESPAR, todas estão muito aquém na carga horária referente à macro área de Ensino e Pesquisa, que contempla cerca de $16 \%$ das competências previstas nas DCN's.

Também é possível observar que as matrizes curriculares apresentam divergência em relação à prática mensurada pelas ART's, uma vez que cerca de $86 \%$ destas encontram-se ligadas à macro área de Mapeamento/Geotecnologias.

Os cursos com matrizes curriculares mais especializadas na área de Estudos e Análise Ambiental são os da UNICENTRO, com maior percentual (30\%); e o da UNESPAR, com maior carga horária efetiva (1048h).

Já os cursos com mais disciplinas especializadas na área de Planejamento Territorial são os da UEM, com maior percentual (30\%) e, o da UNILA com maior carga horária efetiva (952h).

O curso de Geografia da UNIOESTE é ao mesmo tempo o que apresenta maior percentual e carga horária efetiva dedicada à área de Mapeamento e Geotecnologias (24\% e 714h), enquanto o curso da UNESPAR é o que apresenta maior ênfase na área de Ensino e Pesquisa (16\% e 720h).

\section{CONCLUSÃO}

No que se refere à comparação da Lei 6.664/79 com as DCN's, observa-se que houve um enriquecimento na macro área de Mapeamento Geotecnologias. As competências previstas pelas DCN's mantiveram as macro áreas já identificadas pela Lei 6.664/79 e permitiram a identificação de mais duas macro áreas, Ensino / 


\section{EXERCÍCIO PROFISSIONAL DO GEÓGRAFO NO ESTADO DO PARANÁ: CONVERGÊNCIAS E DIVERGÊNCIAS ENTRE A LEI DO GEÓGRAFO, AS DIRETRIZES CURRICULARES NACIONAIS, AS MATRIZES CURRICULARES E A PRÁTICA PROFISSIONAL}

Pesquisa e, Turismo. A tabulação das competências relacionadas pelas DCN's mostra que as mesmas apresentam maior ênfase na área de Análise Ambiental, que passou a responder por $32 \%$ das competências.

A ênfase dada pelas DCN'S à macro área de Mapeamento/Geotecnologias coaduna com a prática profissional observada pelo recolhimento de ART'S no Estado.

As ART's mostram que a atuação dos Geógrafos se faz presente em praticamente todo o Estado, sendo as regiões centro-norte, centrosul e oeste as de menor atuação.

A produtividade, contudo, não segue a densidade de profissionais nos municípios. Guarapuava é o município com o maior número de ART's no Estado, apesar de possuir apenas 23 Geógrafos.

A principal macro área de atuação dos geógrafos no Estado é a de Mapeamento/Geotecnologias, o que corresponde a $86,7 \%$ do total de ART's recolhidas, com ênfase nas atividades ligadas à topografia. Análise Ambiental e Planejamento Territorial respondem por menos de $10 \%$ das ART's recolhidas no Estado. Poucas ART's possuem relação, enquanto denominação, com as atribuições e competências listadas pela Lei e pelas DCN's.

A macro área de Mapeamento e Geotecnologias cresceu em função dos avanços tecnológicos e encontra-se associada a todas as demais macro áreas de atuação. Este fato reforça sua importância e a observação dos percentuais de horas dedicadas a esta temática nas matrizes curriculares dos cursos de bacharelado.

Este artigo levanta um debate inicial sobre a temática da estruturação curricular dos cursos de bacharelado em Geografia do estado do Paraná frente à legislação, DCN's e demandas sociais em torno de sua atuação profissional. Tanto a Lei como as DCN's apontam para uma diversificada atuação profissional, a qual não se reflete nas ART'S recolhidas, o que suscita uma reflexão por parte dos cursos.
Cabe a todos envolvidos com a formação e exercício profissional, a análise dos resultados apresentados com vistas a avaliar a pertinência dos mesmos e a necessidade de melhorias.

\section{6 .AGRADECIMENTOS}

Os autores deste artigo agradecem ao CREA-PR, na pessoa do Eng. Giovani Castoldi, pela colaboração no sentido de ceder os dados e informações ora apresentados e à Mayara Kurta, discente de bacharelado do curso de Geografia da UNICENTRO, pelo apoio na quantificação de dados apresentados.

\section{REFERÊNCIAS}

BERTIN, J.; Semiology of Graphics: Diagrams, Networks, Maps. Trad.: BERG, W. J. Madison: ESRI Press, 2011.

BRASIL. Lei no 6.664, de 26 de junho de 1979. Disciplina a profissão de Geógrafo e dá outras providências. Diário Oficial da União, Brasília, DF, 27 jun 1979.

BRASIL. Decreto no 85.138, de 15 de setembro de 1980. Regulamenta a Lei no 6.664, de 26 de junho de 1979, que disciplina a profissão de Geógrafo, e dá outras providências. Diário Oficial da União, Brasília, DF, 17 set 1980.

BRASIL. Lei no 7.399, de 04 de novembro de 1985. Altera a redação da Lei no 6.664, de 26 de junho de 1979, que disciplina a profissão de Geógrafo. Diário Oficial da União, Brasília, DF, 05 nov 1985.

BRASIL. Lei no 9.394, de 20 de dezembro de 1996. Estabelece as diretrizes e bases da educação nacional. Diário Oficial da União, Brasília, DF, 23 dez 1996.

BRASIL. Ministério da Educação. Conselho Nacional de Educação. Parecer CNE/CES 492/2001. Trata das Diretrizes Curriculares Nacionais dos cursos de Filosofia, Historia, Geografia, Serviço Social, Ciências Sociais, Letras, Biblioteconomia, Arquivologia e Museologia. Diário Oficial da União, Brasília, 9 jul 2001.

BRASIL. Ministério da Educação. Conselho Nacional de Educação. Parecer CNE/CES 67/2003. Referencial para as Diretrizes Curriculares 
Nacionais - DCN dos Cursos de Graduação. Diário Oficial da União, Brasília, 2 jun 2003.

CORREA, R. L. Reflexões sobre paradigmas, geografia e contemporaneidade. Revista da Anpege, v. 7, n. 1, p. 59-65, 2011.

FALCO, J. G. Estatística aplicada. Cuiabá: EdUFMT, 2008.

GODOY, P. R. T. DE. Paradigmas e Geografia. Revista da ANPEGE, v. 7, n. 1, p. 67-80, 2011.

LISBOA, F.; BARBOSA, A. Formação em psicologia no Brasil: um perfil dos cursos de graduação. Psicologia Ciência e Profissão, v. 29, n. 4, p. 718737, 2009.

MACEDO, D. C. de; MATOS, S. N. U. Extração de conhecimento através da mineração de dados. Revista de Engenharia e Tecnologia, v. 2, p. 2230, 2010.

MACEDO, L. Ensaios Pedagógicos: Como construir uma escola para todos? Porto Alegre: Artmed Editora, 2009.

MARCONI, M. de A.; LAKATOS, E. M. Fundamentos de metodologia científica. São Paulo: Atlas, 2003.

MEC - MINISTÉRIO DA EDUCAÇÃO. Instituições de Educação Superior e Cursos Cadastrados. Disponível em: <https://goo.gl/ci3mtj>. Acesso em: 17 jun 2016.

ROSA, R. Geotecnologias na Geografia aplicada. Revista do Departamento de Geografia, v. 16, p. 81-90, 2005.

SUERTEGARAY, D.; NUNES, J. A natureza da Geografia Física na Geografia. Revista Terra Livre, v. 17, p. 11-24, 2001. 